\title{
Study Regarding the Relationship between Nutritional Status and Oral Health in the Elderly Patients
}

\begin{abstract}
AMELIA SURDU ${ }^{1}$, LIVIA BOBU ${ }^{1 *}$, DANIEL CIOLOCA ${ }^{1}$, CLAUDIU TOPOLICEANU' ${ }^{1}$, CRISTIANA FILIP², ANCUTA GORIUC ${ }^{1}$, MIHAELA MONICA SCUTARIU'*, ALICE MURARIU1.

${ }^{1}$ Grigore T. Popa University of Medicine and Pharmacy, lasi, Faculty of Dental Medicine, 16 Universitatii Str.,700115, Iasi, Romania ${ }^{2}$ Grigore T. Popa University of Medicine and Pharmacy, lasi, Faculty of Medicine, 16 Universitatii Str., 700115, lasi, Romania

The aim of study was to investigate the relationship between oral health and nutritional status in a population of elderly patients with systemic chronic or acute pathology. Materials and method: Prospective crosssectional clinical investigation of 115 aged patients ( $>60$ yo; mean age 66.2) from the Clinical Foundation, Faculty of Dental Medicine, University of Medicine and Pharmacy of lasi. In the first stage of the study, the patients (able to understand and communicate) were submitted to a mini-test for the assessment of the mental status (MMSE) . In the second stage of the study, a questionnaire was used to record demographic and socioeconomic data of the subjects as well as information regarding systemic status and nutritional facts. In the third stage of the study, the nutritional status was evaluated by using Mini-Nutritional Assessment questionnaire (MNA). Finally, the oral status was evaluated by using clinical and radiographical exams as well as geriatric oral health assessment index (GOHAl). Results: Of the 60 old adults, $6 \%$ were severely malnourished, and $37.4 \%$ presented malnourished risk. $49.6 \%$ of the old people had difficulties eating firm foods, $25 \%$ of them being unable to prepare meals. Regarding oral status, only $5.2 \%$ had at least 20 natural teeth, $55.6 \%$ required dental care for decayed or broken teeth, $69.6 \%$ were affected by xerostomia, $21 \%$ of the completely or partial edentulous people were untreated by removable dentures, $25 \%$ of the edentulous patients complained by ill-fitted removable dentures. Conclusion: Lack of education, treatment with over 3 drugs daily, physical inability to buy foods or to prepare meals, as well as the difficulties eating firm foods are strongly associated with poor nutritional status. Also, the need for dental care was associated to nutritional deficiency.
\end{abstract}

Keywords: oral diagnosis, elderly, nutritional status, oral health, systemic pathology

The increase of the proportion of aged people in total population is a global phenomenon, with an incrementfrom only $8 \%$ in 1950 , to $10 \%$ in 2010 , being estimated to reach $21 \%$ in 2050 [1]. In Romania, due to demographic changes (migration of young adults) and low birth rate, the old population (>60) reached $21 \%$ [2]. This percent is similar to other developed countries like J apan (26\%), Italy (21\%), Germany (21\%), Sweden (20\%), UK (18\%) [3].

Elderly people are a population with unsatisfactory oral health and high risk of poor nutritional status, due to physical, physiological, and psychosocial factors [4]. The diet of old people is characterized by low energy and nutrient content, as well as deficiencies in calcium, zinc, magnesium, iron, vitamin D, vitamin B6, vitamin B12, vitamin $\mathrm{E}$, thiamin, retinol, carotenes, and folic acid $[5,6]$. The supply of proper oral health care to old people is deficient due to inadequate resources and time, the lack of motivation and interest for oral health care of seniors or their relatives, changed eating habits or saliva quality and composition, and behavioral changes in terms of oral hygiene, and decrease income as well [7].

Despite the evidences that suggest the implications of the unsatisfactory oral health for general systemic health, the association between oral health and nutritional status is still debatable [8-10].

\section{Experimental part}

We aimed to investigate the relationship between oral health and nutritional status in a population of elderly patients with systemic chronic or acute pathology.

\section{Methods}

The research consisted of a prospective, cross-sectional clinical investigation of 115 aged patients (> 60yo; mean age 66.2) from Clinical Foundation, Faculty of Dental Medicine, Grigore T. Popa University of Medicine and Pharmacy of lasi. The inclusion criteria were as follows: patients without dialysis, cancer, malabsorption syndrome, able to understand and communicate. The demographic data of the study group were collected, the information regarding the systemic status of the study group being either recorded. Nutritional inputalong with data related to the oral health of the study group were also collected. In the second stage of the study, a questionnaire was used to record demographic and socioeconomic data of the subjects (such as age, gender, life conditions, education level, income), as well as data regarding systemic status. The medical data included the type and evolution of systemic pathology (diabetes, cardiovascular pathology, respiratory diseases, rheumatoid arthritis), as well as cure and medication. The required nutritional informations were related to the possibility to prepare the meals, the foods quantity and texture. Moreover, weight and height were recorded for a proper BMI (body mass index) estimation.

In the third stage of the study, the nutritional status was evaluated by using Mini-Nutritional Assessment questionnaire (MNA). The questionnaire included anthropometric evaluation, dietfeatures, environment data, as well as self-assessment of the systemic health and nutritional status. The final score allowed the classification 
of subjects in three categories: proper nutritional status

(>23.5); malnutrition risk (17-23.5); malnutrition (<17).

In the fourth stage of the study, the oral health status was determined, by using clinical and radiographical exams. Also, it was used geriatric oral health assessment index (GOHAl) to determine subjects' self-perception of the oral health status and need for oral care. The oral health recorded parameters were as follows:

-number of the remaining teeth $(\geq 20,<20$, total edentation);

-type and status of dentures (well-fit, mal-fit);

-pain during mastication;

-xerostomia.

The GOHAl questionnaire (12 questions) was used to evaluate the self-perception of the patients for their own oral health-related issues and the need for oral health care, regarding:

-oral functions;

-pain and discomfort due to the oral pathology;

-psychological and social aspects related to the oral pathology.

-the need for dental treatment (considered for patients with $\mathrm{GOHAl} \geq 14$ ).

\section{Results and discussions}

The demographic data of the study group are presented in the table 1, while data regarding the systemic status of the study group are presented in the table 2 . Referring to the nutritional status of the study group the results are depicted in table 3.

The main collected data related to the oral health of the study group are presented in table 4, while main results concerning the GOHAl score for all the subjects included in the study are included in table 5.

In the first stage of the study, the patients were submitted to a mini-test (MMSE) for the assessment of the mental status (patient able to understand and communicate)

Table 1

DEMOGRAPHIC DATA IN THE STUDIED GROUP

\begin{tabular}{|c|c|}
\hline Study group data & $\%$ \\
\hline Age groups: & $8.7 \%$ \\
60 & $45.2 \%$ \\
$61-70$ & $27 \%$ \\
$71-80$ & $19.1 \%$ \\
$>80$ & $51.3 \%$ \\
\hline Gender: & $48.7 \%$ \\
\hline Females & $56.5 \%$ \\
Males & $44.4 \%$ \\
\hline Life conditions: & \\
Married & $48.7 \%$ \\
Single & $33.9 \%$ \\
\hline Education level: & $17.4 \%$ \\
\hline Primary school & \\
Highschool & Faculty \\
\hline
\end{tabular}

Table 2

SYSTEMIC STATUSDATA

\begin{tabular}{|c|c|}
\hline Study group data & $\%$ \\
\hline Number of chronic diseases: & \\
0 & $9.5 \%$ \\
1 & $22.6 \%$ \\
2 & $32.2 \%$ \\
3 & $35.7 \%$ \\
\hline Treatment with at least 3 drugs: & \\
Yes & $54.8 \%$ \\
No & $45.2 \%$ \\
\hline
\end{tabular}

Table 3

NUTRITIONAL DATA

\begin{tabular}{|c|c|}
\hline Study group data & $\%$ \\
\hline Able to buy foods: & $60.9 \%$ \\
Yes & $15.6 \%$ \\
Sometimes & $23.5 \%$ \\
\hline No & $55.6 \%$ \\
\hline Able to cook: & $19.4 \%$ \\
Yes & $23.5 \%$ \\
Sometimes & $60.9 \%$ \\
No & $39.1 \%$ \\
\hline Eating: & \\
Family & $49.6 \%$ \\
Single & $50.4 \%$ \\
\hline Trouble with firm foods:
\end{tabular}

Table 4

ORAL HEALTH STATUSIN THE STUDIED GROUP

\begin{tabular}{|c|c|}
\hline Study group data & $\%$ \\
\hline Number of remaining teeth: & $5.2 \%$ \\
20 & $25.2 \%$ \\
ET & $69.6 \%$ \\
\hline Edentation: & $69.9 \%$ \\
Yes & $30.4 \%$ \\
No & $59.6 \%$ \\
\hline Prostheses: & $19.2 \%$ \\
Yes, well-fitted & $21.1 \%$ \\
Yes, ill-fitted & \\
No & $69.6 \%$ \\
Xerostomia: & $30.4 \%$ \\
\hline Yes & \\
No &
\end{tabular}

Table 5

GOHAISCORE

\begin{tabular}{|c|c|}
\hline Study group data & $\%$ \\
\hline Needfor treatment: & $55.6 \%$ \\
Yes & $44.4 \%$ \\
\hline No & $39.1 \%$ \\
\hline GOHAI scores: & $14.8 \%$ \\
2 & $22.6 \%$ \\
3 & $23.5 \%$ \\
4 & \\
\hline
\end{tabular}

(table 6). Only subjects with scores $24-30$, with acceptable cognitive status were included in study.

The relationship between the nutritional status and demographic data is given in table 7 . The results related to the relationship between the nutritional status and the systemic status are presented in the table 8 . The results related to the relationship between the nutritional status and the nutritional subjects' features are presented in the table 9.

The results related to the relationship between the nutritional status and the oral health are presented in the table 10, while main results concerning the relationship between the nutritional status and GOHAl score are depicted in table 11 . The nutritional data showed that $25 \%$ of subjects were unable to prepare meals, and $23.5 \%$ were unable to buy foods. $6 \%$ were severely malnourished, and $37.4 \%$ presented malnutrition risk. $49.6 \%$ of the old subjects evaluated presented difficulties in eating firm foods.

Regarding the systemic status, $35.7 \%$ of subjects were diagnosed with at least 3 chronic diseases (most frequently, diabetes with hypertension and osteoporosis), and $54.8 \%$ administered more than three drugs. In what concerns the oral status, only $5.2 \%$ of subjects presented 


\begin{tabular}{|c|c|c|}
\hline MMSE Score & Stage & Features \\
\hline 30 & Normal & Absent symptoms \\
\hline $24-27$ & Early cognitive disorders & Amnesiac symptoms \\
\hline $21-23$ & Mild phase & Mild cognitive deficiency \\
\hline $18-20$ & Moderate phase & Clear cognitive deficiency \\
\hline $15-17$ & Moderate-severe phase & $\begin{array}{c}\text { Cognitive and psychiatric symptoms } \\
\text { Assistance required }\end{array}$ \\
\hline $12-16$ & Severe phase & Assistance required for daily activities \\
\hline $0-11$ & Worse phase & Institutionalized assistance \\
\hline
\end{tabular}

Table 6

MMSESCORE (MENTAL STATUS)

Table 7

DEMOGRAPHIC DATA vs. NUTRITIONAL STATUS

$40.7 \%$

$46.4 \%$

Males

Life conditions:

Married

Single

Education level:

Primary school

Highschool

Faculty

\begin{tabular}{|c|c|c|}
\hline Study group data & $\begin{array}{c}\text { Good nutritional } \\
\text { status }\end{array}$ & $\begin{array}{c}\text { Poor nutritional } \\
\text { status }\end{array}$ \\
\hline Number of chronic diseases: & & \\
0 & $63.6 \%$ & $36.4 \%$ \\
1 & $65.4 \%$ & $34.6 \%$ \\
2 & $64.9 \%$ & $35.1 \%$ \\
3 & $58.5 \%$ & $41.5 \%$ \\
\hline Treatment with at least 3 arugs: & $42.9 \%$ & $57.1 \%$ \\
Yes & $73.1 \%$ & $26.9 \%$ \\
\hline No &
\end{tabular}

\begin{tabular}{|c|c|c|}
\hline Study group data & Good nutritional status & Poor nutritional status \\
\hline Able to buy foods: & $77.1 \%$ & \\
Yes & $22.2 \%$ & $22.9 \%$ \\
Sometimes & $25.9 \%$ & $77.8 \%$ \\
No & $80 \%$ & $74.1 \%$ \\
\hline Able to cook: & $35.7 \%$ & $20 \%$ \\
Yes & $27.8 \%$ & $64.7 \%$ \\
Sometimes & $60 \%$ & $72.2 \%$ \\
\hline No & $54.3 \%$ & $40 \%$ \\
\hline Meals: & $45.7 \%$ \\
\hline Family & $43,9 \%$ & $56.1 \%$ \\
Single & $69 \%$ & $31 \%$ \\
\hline
\end{tabular}

\begin{tabular}{|c|c|c|}
\hline Study group data & Good nutritional status & Poor nutritional status \\
\hline Number of remaining feeth: & $66.7 \%$ & \\
20 & $58.9 \%$ & $33.3 \%$ \\
20 & $55 \%$ & $41.1 \%$ \\
ET & $55 \%$ & $45 \%$ \\
\hline Edentation: & $45 \%$ \\
Yes & $60 \%$ & $40 \%$ \\
No & $63.1 \%$ & \\
Prostheses: & $36.9 \%$ \\
Yes, well-fitted & $52.4 \%$ & $47.6 \%$ \\
Yes, ill-fitted & $39.1 \%$ & $59.9 \%$ \\
\hline No & $43 \%$ & \\
Xerostomia: & $57 \%$ \\
Yes & $56 \%$ & $44 \%$ \\
No & \\
\hline
\end{tabular}

at least 20 natural teeth, $55.6 \%$ required dental care for decayed or broken teeth, $69.6 \%$ being affected by xerostomia. $21 \%$ of the completely or partial edentulous people were not treated with removable dentures, $25 \%$ of the edentulous patients complaining of poorly-fitted removable dentures.
This study describes the status of oral health and nutrition for a group of aged patients requiring oral health care. The study uses validated assessment tools and qualified dental practitioners which practice daily on elderly people in the Clinical Foundation, Faculty of Dental Medicine, University of Medicine and Pharmacy of lasi.
Table 8

SYSTEMIC STATUSDATA vs. NUTRITIONAL STATUS

Table 9

NUTRITIONAL DATA vs. NUTRITIONAL STATUS

Table 10

ORAL STATUS IN THE STUDIED GROUP 


\begin{tabular}{|c|c|c|}
\hline Study group data & Good nutritional status & $\begin{array}{c}\text { Poor nutritional } \\
\text { status }\end{array}$ \\
\hline $\begin{array}{c}\text { Need for treatment: } \\
\text { Yes }\end{array}$ & $46.9 \%$ & $53.1 \%$ \\
No & $68.6 \%$ & $31.4 \%$ \\
\hline GOHAI scores: & $68.9 \%$ & $31.1 \%$ \\
1 & $64.7 \%$ & $35.3 \%$ \\
3 & $50 \%$ & $50 \%$ \\
4 & $37 \%$ & $63 \%$ \\
\hline
\end{tabular}

Table 11

GOHAl score
Our study reveals a low proportion of severe malnourished old people (6\%), and moderate proportion of the old subjects with risk of malnutrition (37.4\%), despite relative high proportion of elderly with difficulties in eating firm foods (49.6\%). Considering the high percentage of subjects affected by xerostomia (69.6\%), decayed and broken teeth (55.6\%), total or partial extended edentation (94.8\%), as well as the proportion of subjects untreated or wearing unfitted removable dentures (21\%), we concluded that risk of malnutrition can be influenced by the oral pathology. Cofounding factors must be considered as well, as all subjects were affected by chronic or acute systemic disorders.

Other studies on the same area found different results upon the nutritional status: $62 \%$ were malnourished ( $55 \%$ moderately malnourished, $7 \%$ severely malnourished), $82 \%$ needed a dental referral. More people who had decayed or broken natural teeth $(77 \%)$ encountered difficulties eating firm foods than those who had healthy natural teeth $(23 \%)$ [8]. Significant statistical differences were found between old people with normal diettexture and those with hardship eating firm foods related to their oral health status. $58 \%$ of the subjects with a normal diet texture had unhealthy changes to their teeth compared to $100 \%$ of subjects who had a modified texture diet. $68 \%$ of the subjects with good nutritional status reported never having deficiencies eating hard foods, compared to only $30 \%$ of moderately malnourished subjects. The conclusion of this study was that malnutrition was strongly associated with poor life quality and modified diet texture was associated with poor nutritional status [8]. The differences are related to the pool of old people as this study was performed on aged care residents with higher degree of dependency and lower levels of health care than patients from our study group.

During our research, a low level of perception of oral health (highest GOHAl score) was associated with elevated risk of nutritional deficiency (MNA <24), result similar with other study that reported a 3.41 higher nutritional risk for elderly people with poor perception of their oral health [11].

Only a few studies were focused on the relation between oral health, nutrition and quality of life are scarce [12, 13]. A systematic review of the relationship between poor nutrition and oral health status in the elderly found lack of methodological robustness and the use of validated assessments. Of the 16 considered studies, only 3 of them used a validated assessment tool [14]. In this context, interpretation of the literature data is challenging, due to the absence of universally agreed tests and the multifactorial nature of both, poor oral health and malnutrition along with a range of confounding factors [14]. Interpretation of the results reported by studies must consider that poor oral health and xerostomia have previously been associated with reduced chewing function and avoidance of firm foods by elderly people [15]. Also, the poor dental status and the decrease of the life quality can influence meals time and loneliness which will negatively impact dietary intake $[15,16]$.
Oral pathology can lead to improper nutritional status, by pain and discomfort related to dental caries, periodontal disease and ill-fitted fixed dentures or removable dentures [17-23]. Also, even treated with removable dentures, the extended partial edentation or total edentation affect severely the digestive function and the nutritional status $[24,25]$.

This category of researches highlights the role of maintaining a proper oral health as improper health status can lead to underweight, that increases the risk of infections and mortality [26,27].

Considering these data, the management of the elderly requires a multidisciplinary, biomedical, psychological, social, socio-demographic, administrative, legal, economic, ethical and affective approach [28-30].

The interpretation of the results reported by various researches is difficult due to the heterogeneity of populations in anthropometric and nutritional parameters and the use of different assessment tools related to oral health status and nutritional status.

Further studies are required to investigate if regular oral health assessments and therapeutic plans in elderly can improve or reduce the decline of the nutritional status. Also, specific researches performed on large populations can better establish the relation between the growth of the nutritional status and the improvement of oral health status and quality of life. Recommendations for future practice include increasing training and education of RACFs in terms of oral health care and its connection with nutritional status and quality of life, increased access to dental professionals in RACFs and the importance of concurrent referrals to dietitians when dental issues are identified.

\section{Conclusions}

The paucity of education, treatment with over 3 drugs daily, physical inability to buy foods or to prepare meals, as well as the difficulties in eating firm foods are strongly associated with poor nutritional status. Moreover, our study empowers for the need for dental care for these subjects, as the shortfall of the oral status was strongly associated to nutritional deficiencies.

\section{References}

1.D'ALBIS, H. COLLARD, F. Demographic Research. 29, no. 23, 2013, p 618-639.

2.***http://www.cnpv.ro/pdf/analize2014/Populatia-varstnica-aRomaniei-la-orizontul-anului-2060.pdf,

3.***https://data.worldbank.org/indicator/SP.POP.65UP.TO.ZS. Population ages 65 and above. 2015

4.GIL-MONTOYA, J .A., FERREIRA DE MELLO, A.L., ROCÍO BARRIOS, M., GONZALEZ-MOLES, M.A., Bravo M. Clin Interv Aging. 2015; 10: 461-467.

5.MONTGOMERY, S.C, STREIT, S.M., BEEBE, M.L., MAXWELL, P.J . Nutr Clin Pract. 29, no. 4, 2014, p 435-444.

6.HURJUI, L., HURJUI, I., MOSCU, M., POPOVICI, D., GRADINARU, I. Rom J of Oral Rehab, 9, no. 4, 2017, p18. 
7.CIURCANU, O., CIUPILAN, C., SALCEANU, M., MELIAN, A., AGOP FORNA, D., SCUTARIU, M.M. Rom J of Oral Rehab, 10, no. 1, 2018, p 108-113.

8.HUGO, C., COCKBURN, N., FORD, P., MARCH, S., ISENRING, E. J Nursing Home Res. 2, 2016, p 118-122.

9.GRADINARU, I., HURJUI, L.L., HURJUI I, ANTOHE, M.E., Rom J of Oral Rehab, 10, no. 4, 2018, p114.

10.VASLUIANU, R.I., FORNA, N.C., BACIU, E.R., ZALTARIOV, M., VASILIU, L., MURARIU, A. Rev.Chim. (Bucharest) 69, no.7, 2018, p. 1714.

11.MESAS, A.E., MAFFEI DE ANDRADE, S., SARRIA CABRERA, M.A., RIBEIRO DE CARVALHO BUENO, V.L. Brazil. Rev. Bras. Epidemiol. 13, no.3, 2010,

12.COUSSON, P.Y., BESSADET, M., NICOLAS, E., VEYRUNE, J.L., LESOURD, B., LASSAUZAY, C. Gerodontology. 29, no. 2, 2012. e685e92.

13.PALMER, C.A. Dental Clinics of North America. 47, no. 2, 2003, p 355-71.

14.VAN LANCKER, A., VERHAEGHE, S., VAN HECKE, A., VANDERWEE, K., GOOSSENS, J ., BEECKMAN, D. Int J of Nursing Studies. 49, no. 12, 2012, p 1568.

15.BUDTZ-J ØRGENSEN, E., CHUNG, J.P., RAPIN, C.H. Best Practice $\&$ Research Clinical Gastroenterology. 15, no. 6, 2001, p 885-96. 16.RAYNAUD-SIMON, A., LESOURD, B. Malnutrition in the elderly. Clinical consequences. Presse MEdicale. 29, no. 39, 2000, p 2183.

17.TOUGER-DECKER, R., MOBLEY, C.C.. Position of the American dietetic association: oral health and nutrition. J Am Diet Assoc. 107, 2007, p 1418-1428.

18.SUFARU, I.G., SOLOMON, S.M., PASARIN, L., MARTU-STEFANACHE, M.A., OANTA, A.C., MARTU, I., CIOCAN PENDEFUNDA, A., MARTU, S. Rom J of Oral Rehab, 8, no.4, 2016, p 42-46.

19.URSARESCU, I.G., PAVAL, D., SOLOMON, S.M., PASARIN, L., BOATCA, M., NICOLAICIUC, O., NITESCU, D.C., MARTU, S. Rom J of Oral Rehab, 8, no. 1, 2016, p 97-103.
20.ROZALINA, B., TARTAU MITITELU, L., REZUS, C., FILIP, C., PINZARIU, A.C., REZUS, E., POPA, G.E., PANAINTE, A., LUPUSORU, C.E., BOGDAN, M., PAVEL, L., LUPUSORU, R.V. Rev.Chim. (Bucharest) 69, no. 10, 2018, p 2899-2903.

21.SCUTARIU M.M, CIUPILAN, C., SALCEANU, M., MELIAN, A., AGOP FORNA, D., SIOUSTIS, I., CIURCANU, O. Rom J of Oral Rehab, 10, no. 1, 2018, p 128-132.

22.ALBU, E., LUPASCU, D., FILIP, C., JABA, I., ZAMOSTEANU, N. Farmacia, 61, no. 6, 2013, p 1167-1177.

23.TOPOLICEANU, C., GHIORGHE, C.A., TOMA, V., ANDRIAN, S., IOVAN, G., STOLERIU, S., PANCU, G., NICA, I., SALCEANU, M., Rev Chim. (Bucharest), 70, no. 4, 2019, p 1333-1336.

24.FORNA, N., DE BAAT., C, BRATU, D, LASCU, L., MERCUT, V., PETRE, A., POPSOR, S., TRAISTARU, T. Protetica Dentara, vol. II, Edit. Enciclopedica, Buc., 2011.

25.NICOLAE, V; CHISCOP, I; CIORANU IBRIC, V.S., MARTU, M.A., LUCHIAN, A.I., MARTU, S., SOLOMON, S.M., Rev Chim. (Bucharest), 66, no. 12, 2015, p 2121-2123

26.*** World Health Organization. Physical status: the use and interpretation of anthropometry. WHO Technical Report Series 84; Geneva WHO; 1995.

27.NITESCU-KAPPENBERG, D.C., MIHAI, C., OANTA, C., MARTU, I., VOLOVAT, S.R., MARTU, S., Rev. Chim. (Bucharest), 68, no. 3, 2017, p 549-552.

28.DOSCAS, A.R., BALAN, M., CIOFU, M.L., FORNA, D., MARTU, M.C., POPESCU, E., Rev. Chim. (Bucharest), 68, no. 6, 2017, p. 1325-1328. 29.CEPOI V, ALEXA ID, ILIE CA, ALEXA O. Rev Rom de Bioetica, 12, no. 3, 2014, p 12-18.

30.GHEORGHE, D.N., FOIA, L., TOMA, V., SURDU, A., HERASCU, E., POPESCU, D.M., SURLIN, P., VERE, C.C., ROGOVEANU, D. J. of Immunology Research. Article Number: 8720101 Published: 2018

$\overline{\text { Manuscript received:16.01.2019 }}$ 